\title{
Estimating the Risk of Phthalates Exposure via Tea Consumption in the General Population
}

\author{
Mohammad Mehdi Amin ${ }^{\mathrm{a}, \mathrm{b}}$, Foruz Rastegari ${ }^{\mathrm{b}}$, Parinaz Poursafa ${ }^{\mathrm{a}, \mathrm{b}}$, And Karim \\ EBRAHIM $^{\mathrm{a}, \mathrm{b}^{*}}$ \\ ${ }^{a}$ Department of Environmental Health Engineering, School of Health, Isfahan University of Medical Sciences, \\ Isfahan, Iran \\ b Environmental Research Center, Research Institute for Primordial Prevention of Non-communicable Disease, \\ Isfahan University of Medical Sciences, Isfahan, Iran \\ * Corresponding author \\ k.najafabady@sbmu.ac.ir \\ TEL: +98-31-3792-3223 \\ FAX: $+98-31-36682509$
}

Received: 28 February 2017; Published online: 18 April 2018

\begin{abstract}
Four common phthalic acid esters (PAEs) levels in tea fusions samples prepared from three types of tea bags (green, black and white) of ten commercial brands were extracted from the infusions by a dispersive liquid-liquid micro extraction method and determined by GC-MS.

PAEs were not found in white tea samples. Residue levels of total phthalic acid esters (TPAEs) in black and green teas showed no significant difference (median $=367.5$, Interquartile range $=244.7-667.5$ and median $=381$, Interquartile range $=188.7-688.2 \mu \mathrm{g} / \mathrm{kg}$ respectively). DEHP levels in green teas were significantly higher than those in black teas (Median $=93.5$ and 204 respectively). Total phthalate esters (TPAEs) levels in flavored teas were about two-fold higher than in non-flavored teas. The four commercial brands tested contain significant levels of DEHP when compared to other brands. Essential oils and essences that were added to tea for improvement of color and taste could be the main sources of PAEs contamination.

If oral absorption of phthalates were assumed to be $100 \%$, the maximum daily exposure levels to TPAEs via tea consumption (due to consumption of 5 cups of tea prepared from the tea containing the highest levels TPAEs) were estimated to be $230 \mathrm{e}^{-4} \mu \mathrm{g} / \mathrm{kg}$ bw/Day, which are far lower than the regulation levels set by the expert panels on regularly toxicity.
\end{abstract}

Keywords: Phthalates; Tea; Exposure assessment

\section{Introduction}

Phthalate esters (PAEs) are dialkyl or alkyl/aryl esters of phthalic acid and are widely used as plasticizers and additives for production of many daily products including plastics, pesticides, paints and cosmetics (Del Carlo et al., 2008). PAEs do not covalently bond to the polymer molecules and easily release from plastic products (Glue et al., 2005) which leads to wide distribution of these materials in the environment. Phthalates are described as being among the most abundant environmental and food contaminants (Latini, 2005).

Di-(2-ethylhexyl) phthalate (DEHP) is the most commonly used plasticizer. Dimethyl phthalate (DEP), diethyl phthalate (DEP), di- $n$-butyl phthalate (DnBP), and benzyl butyl phthalate 
(BBP) also widely used worldwide (Kamrin, 2009). Due to their potential risk for human health and environment, several of PAEs have been included in the priority list of pollutants of different national and international organizations (Heudorf, Mersch-Sundermann, \& Angerer, 2007).

Certain phthalate esters, as well as their metabolites, may have adverse effects on human health, particularly on liver, kidney and testis. Potential endocrine disrupting effects and carcinogenic properties are also reported. Metabolic products of phthalates are shown to have developmental and reproductive toxicity, mainly on the male reproductive system. Some of the phthalates interfere with the function of the endocrine system, which is responsible for growth, sexual development and many other essential physiological functions in both sexes.

Several adverse effects due to phthalate exposure including decreased fertility, foetal defect (growth retardation and dysmorphogenesis), reduced survival of offspring, altered hormone levels, uterine damage, male reproduction abnormalities such as reduced sperm production and motility, Sertoli cell damage and Leyding cell tumors have been demonstrated in animal studies (Martino-Andrade \& Chahoud, 2010; Montuori, Jover, Morgantini, Bayona, \& Triassi, 2008).

Tea is the most frequently consumed beverage next to water, with about 20 billion cups consumed daily worldwide (Shen \& Chen, 2008). Tea is made from the processed leaves of the tea plant (Camellia sinensis and Camellia assam$i c a$ ). Black, green and white teas are the most common types of tea and are distinguished on the basis their respective manufacturing methods. Black tea is fermented; green tea is dried and roasted but not fermented; white tea is made from buds and young leaves and just dried without further fermentation or other procedures (Chacko, Thambi, Kuttan, \& Nishigaki, 2010). It is estimated that 2.5 million metric tons of dried tea are produced annually, of which $75 \%$ is processed as black tea consumed in many countries (Karimi et al., 2008).

Tea has received increasing attention for its beneficial health properties that include the prevention of cardiovascular diseases, skin cancer, coronary artery disease, Parkinson's disease and my- ocardial infarction (Qin \& Chen, 2007)). However, several studies have demonstrated that tea leaves may also contain some harmful contaminants, which can be released into infusions; such as, considerable levels of heavy metals including lead, cadmium, arsenic, mercury (Han, Mihara, \& Fujino, 2014; Shaltout, Abdel-Aal, Welz, \& Castilho, 2013), poly-chlorinated biphenyls (PCBs), fertilizers, pesticides (Beizhen, Weihua, Liping, \& Tiefeng, 2008; Shen \& Chen, 2008) and poly-aromatic hydrocarbons (PAHs) (Lin, Zhu, He, \& Tu, 2006)) are reported in different types of tea infusions. Contaminated cultivation soils, transportation and possessing procedures are suggested as possible sources of these contaminants.

In a recent study by Di Bella, Saitta, La Pera, Alfa, and Dugo (2004) phthalate esters concentrations were measured in tea samples from Italian markets and considerable levels of di-(2-ethylhexyl)-phthalate (DEHP), di-n-butylphthalate (DBP) and diethyl phthalate (DEP) were found in all analyzed samples. That was the first report about phthalate contamination in tea infusions and some subsequent studies have confirmed this contamination (Du, Ma, Qiao, Lu, \& Xiao, 2016; Lu, Du, Qiao, Wang, \& Xiao, 2015). In most of these studies, PAEs levels have been determined in dry tea samples but given that traditionally, tea is prepared by infusion of dry leaves in boiling water, and considering that tea is consumed in the form of infusion by consumers, it is essential to determine the dissolving ratio of PAEs from dried tea to infusion.

Easy preparation and effective advertising from tea producers during last decade has encouraged consumers to use tea bags for tea infusion. The aims of this study were to investigate the presence of 4 common phthalate esters in tea infusions made using tea bags and to study daily dietary intake of these phthalates due to tea consumption.

\section{Materials and Methods}

\section{$2.1 \quad$ Sampling}

This cross-sectional study was conducted in the autumn and winter of 2015 in Iran. In initial field 
investigations, 10 famous brands of tea bag in Iran markets were identified and selected for this study. All brands had operating and hygienic licenses from Iranian Food and Drug Organization of the Ministry of Health. Eight of these brands produce only green and black tea bags. Two of them also produce white tea bags. Based on the information presented on package labels of tea bags, all teas were produced in India (Ceylon) and were packed in Iran.

Each tea bag pack usually contains 20 or 25 tea bags. For the present study, six tea bag packs (three green tea bags and three black tea bags) were purchased randomly from different supermarkets in Isfahan, Iran. All samples were produced during the prior 2 months of sampling time. Three tea bags of each pack were selected randomly, labeled and sent for immediate analysis in the laboratory.

\section{$2.2 \quad$ Materials}

Analytical standards of diethyl phthalate (DEP), Bis(2-ethylhexyl) phthalate (DEHP), dibutyl phthalate (DBP) and benzyl butyl phthalate (BBP) were purchased from Sigma Aldrich (Sigma, St. Louis, USA, catalog number: 41320, 53008, 36735 , and 36927 respectively).

The GC grade acetonitrile, carbon tetrachloride, methanol, and ultrapure water were purchased from the Merck (Darmstadt, Germany).

\subsection{Sample preparation}

Each tea bag contained $2 \pm 10 \%$ g dry tea. In the laboratory, tea bags were opened and dry teas were removed from the bags. Then, the dry teas and the bags were infused separately in 50 $\mathrm{ml}$ boiling ultrapure water for $5 \mathrm{~min}$. The infusion cooled down to room temperature, was filtered and subjected to the process of extraction. To ensure the complete migration of PAEs from leaves to infusion, each tea bag was infused in $50 \mathrm{ml}$ boiling water twice and the infusions were mixed before extraction.

\subsection{Stock and working standard preparation}

A mixed stock standard solution of $1000 \mathrm{ppm}$ of all phthalate esters (DEP, DEHP, DBP and $\mathrm{BBP}$ ) was prepared in methanol. The working standard solutions of $50,10,5,1$ and $0.1 \mathrm{ppb}$ were prepared by spiking white tea infusions with PAEs standards (phthalates-free white tea infusion were prepared by ultrapure water and confirmed by GC-MS analysis). The stock and working standard solutions were stored at $4^{\circ} \mathrm{C}$.

\subsection{Extraction of phthalate esters}

Phthalate esters were extracted from the tea infusion samples by a dispersive liquid-liquid extraction (DLLME) method according to previous work [11] with some modifications. For this purpose, an aliquot of $5 \mathrm{~mL}$ of each sample was placed in a $10 \mathrm{~mL}$ glass test tube with a conical bottom. A mixture of acetonitrile $(0.75 \mathrm{~mL})$ as a dispersive solvent and carbon tetrachloride $(50 \mu \mathrm{L})$ as an extraction solvent were prepared and injected rapidly into the sample solution using $1 \mathrm{~mL}$ Hamilton syringe. After that, a cloudy solution (sample+ acetonitrile/ $\mathrm{CCl}_{4}$ ) was formed and the analytes were extracted into the fine $\mathrm{CCl}_{4}$ droplets. After centrifugation for $5 \mathrm{~min}$ at $4500 \mathrm{rpm}$, the extraction solvent was separated and precipitated to the bottom of the conical test tube (about $50 \mu \mathrm{L}$ ). $2 \mu \mathrm{L}$ of precipitated phase was removed using a $10 \mu \mathrm{L}$ GC/MS microsyringe and injected into the GC system for analysis.

\subsection{Analytical methods}

The extracts were analyzed by gas chromatography/mass spectrophotometry using a quadruple Agilent GC-MSD (Agilent Technologies, Palo Alto, CA, USA) model 7890A coupled to a mass selective detector model $5975 \mathrm{C}$ inert, operated in the electron-impact mode at $70 \mathrm{eV}$. Data recording and instrument control were performed by the MSD ChemStation software (G1701CA; Version C.00.00; Agilent Technologies). Helium $(99.999 \%)$ was employed as carrier gas at the flow rate of $1 \mathrm{~mL} / \mathrm{min}$. The analytes were sepa- 
rated using a capillary column (HP-5, $30 \mathrm{~m}, 0.25$ $\mathrm{mm}$ id., $0.25 \mu \mathrm{m}$ coating thickness). The gas chromatographic conditions were as follows; Injection volume: $2 \mu \mathrm{L}$; split ratio: $1 / 10$; injector temperature: $280^{\circ} \mathrm{C}$. The oven temperature was programmed from $100^{\circ} \mathrm{C}$ (holding for $2 \mathrm{~min}$ ), to $210^{\circ} \mathrm{C}$ at $10^{\circ} \mathrm{C} / \mathrm{min}$ then to $250^{\circ} \mathrm{C}$ at $5^{\circ} \mathrm{C} / \mathrm{min}$ and finally to $280^{\circ} \mathrm{C}$ at $30^{\circ} \mathrm{C} / \mathrm{min}$ keeping the final temperature for $4 \mathrm{~min}$. The MS transfer line and ion source were kept at $280^{\circ} \mathrm{C}$ and $230^{\circ} \mathrm{C}$ respectively. The MS was tuned to selective ion monitoring (SIM) mode with $m / z 69,219$, and 502 for the electron impact (EI) corresponding to perfluoro tetrabutyl amine (PFTBA). Data acquisition was carried out in the full-scan mode $(\mathrm{m} / z$ 149) mode and results were qualified by comparison with the NIST and Wiley's library spectral data bank (G1035B; Rev D.02.00; Agilent Technologies).

\subsection{Method validation}

The validation was performed according to International Conference of Harmonization (ICH) recommendations for linearity, range, accuracy and precision, limit of detection (LOD), limit of quantification (LOQ) and relative recovery (Ermer \& Miller, 2006).

\subsection{Statistical analysis}

Experiments were repeated at least three times (using real and independent samples) and the results are expressed as mean \pm SD. Data were analyzed by Student t-test and analysis of variance (ANOVA) with significance level defined as $p<0.05$ using GraphPad-Prism 5 software (GraphPad-Prism Software Inc., San Diego, USA).

\section{Results}

\subsection{Validation of the method}

This is a highly sensitive, selective and accurate analytical method for phthalate detection and determination in aqueous solutions. A good resolution was achieved for phthalates separation in this method. All four phthalate esters leave the column at 11.4, 14.3, 15.4, 20.6 min as shown in Figure 1.

Quantification was done using the external calibration method showing linear correlations with $\mathrm{R}^{2}>0.98$ for all the target analytes from the range of 1 to $1000 \mathrm{ppb}$. Other method validation parameters are presented in Table 1.

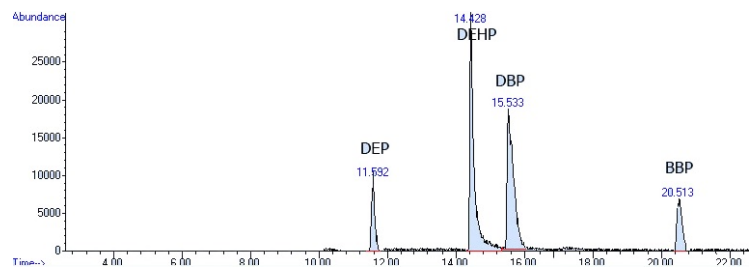

Figure 1: A typical chromatogram of phthalate esters obtained by DLLME-GC/MS under SIM data acquisition mode (m/z: 149)

\subsection{PAEs residues in tea samples}

Minimum, maximum, median and Interquartile range (IQR) of PAEs levels in different types of tea bags from all brands are presented in Table 2. Statistical analysis (shapiro-wilk normality test) had shown that the data do not have a normal distribution, therefore non-parametric statistical tests were used for analysis of data. No amount of any of the phthalates were detected in white tea samples. Application of the MannWhitney test confirms that DEHP and DnPB in green tea samples were significantly higher than black teas but total phthalic acid esters (TPAEs) levels showed no significant differences between black and green teas (Figure 2). Black tea bags from all brands contain considerable levels of different PAEs but in just some of green tea bag brands significant levels of PAEs have been detected (Figure 3-A). In the case of DEHP, this issue is much more obvious and analysis of DEHP in green teas from different brands indicated that four of the tea bag brands contain significantly higher DEHP levels when compared to other six brands (Figure 3-B). Although TPAEs levels showed no significant differences between green and black tea bags but its concentration in 
Phthalates Exposure via Tea Consumption |73

Table 1: Method validation parameters for determination of phthalate esters by DLLME extraction and GC/MS analysis

\begin{tabular}{|c|c|c|c|c|c|c|c|c|c|c|c|c|}
\hline Factor & \multicolumn{4}{|c|}{ R2 } & \multicolumn{4}{|c|}{ LOD (ppb) } & \multicolumn{4}{|c|}{ LOQ (ppb) } \\
\hline PAEs & DEP & DEHP & DBP & $\mathrm{BBP}$ & DEP & DEHP & DBP & $\mathrm{BBP}$ & DEP & DEHP & DBP & $\mathrm{BBP}$ \\
\hline Value & 0.99 & 0.99 & 0.99 & 0.98 & 0.03 & 0.02 & 0.04 & 0.05 & 0.11 & 0.09 & 0.13 & 0.17 \\
\hline \multirow[b]{2}{*}{ Factor } & \multicolumn{8}{|c|}{ RSD\% } & \multirow{2}{*}{\multicolumn{4}{|c|}{ Recovery \% }} \\
\hline & & Withil & days & & & Betwee & days & & & & & \\
\hline PAEs & DEP & DEHP & DBP & BBP & DEP & DEHP & DBP & BBP & DEP & DEHP & DBP & BBP \\
\hline Value & 6.3 & 6.8 & 4.5 & 7.2 & 7.6 & 6.6 & 6.5 & 9.7 & 96.1 & 88.7 & 91.2 & 87.6 \\
\hline
\end{tabular}

flavored teas was significantly higher than nonflavored teas (Figure 4).

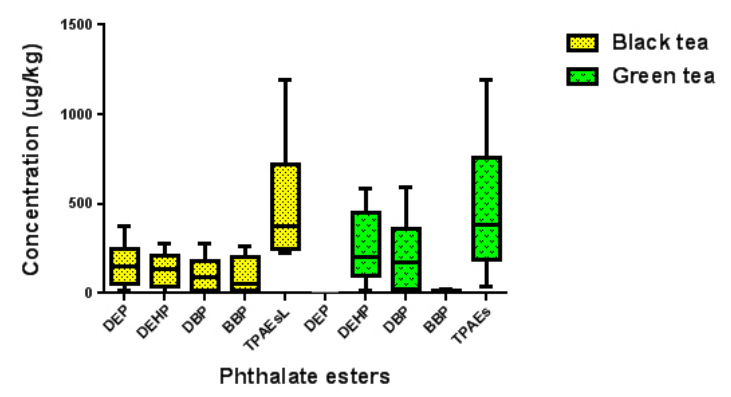

Figure 2: PAEs levels in green and black teas. Data are presented as median (max, min)

\section{Discussion}

Tea plants grow in certain areas of the world, notably in tropical and subtropical areas that have adequate rainfall, acid soils and good drainage. It is estimated that about $80 \%$ of dry teas are produced in the India and China and then exported to other countries (Shah \& Pate, 2016). Therefore, the findings of the present study could be generalized to tea samples used in other countries.

None of the white tea samples contained PAEs residues, indicating that common theories about soil contamination and bioaccumulation of these contaminants in plant proposed for other contaminants such as PAHs and PCBs (Lin et al.,
2006) cannot be applied for plasticizers contamination in tea. It is obvious that processing procedures are definite sources of this contamination. In a study by Mohamed et al., machines or paper coatings during the production steps are proposed as potential sources of plasticizers residues in tea (Mohamed \& Ammar, 2008). Lo Turco, Di Bella, Potorti, Fede, and Dugo (2015) claim that paper, silk or nylon bags are important sources of phthalate contamination in teas, but the results of the present study showed no detectable amounts of PAEs in infusion of tea-free bags in boiling water.

Several reports exist about the use of essential oils and synthetic essences as color, taste and flavors by tea producers. In a study by Di Bella et al. (2004), significant levels of phthalate esters have been detected in essential oils. Likewise, the findings of the current study showed higher levels of PAEs in flavored teas than in non-flavored teas. These findings are in consistent with some previous studies (Lo Turco et al., 2015). On the other hand, PAEs levels in some tea brands are significantly higher than other brands indicated that some essential oils and synthetic essences have been added to tea by certain tea producers to improving the tea taste and color, is the main source of phthalates residues in the tea.

It is generally believed that green tea has numerous health benefits and is safer than black tea (Cabrera, Artacho, \& Gimenez, 2006; Gupta, Saha, \& Giri, 2002), however, our results show that about $50 \%$ of green tea samples contained significant levels of PAEs, specifically the more hazardous ones (EDHP). 
$74 \mid$ Amin et al.
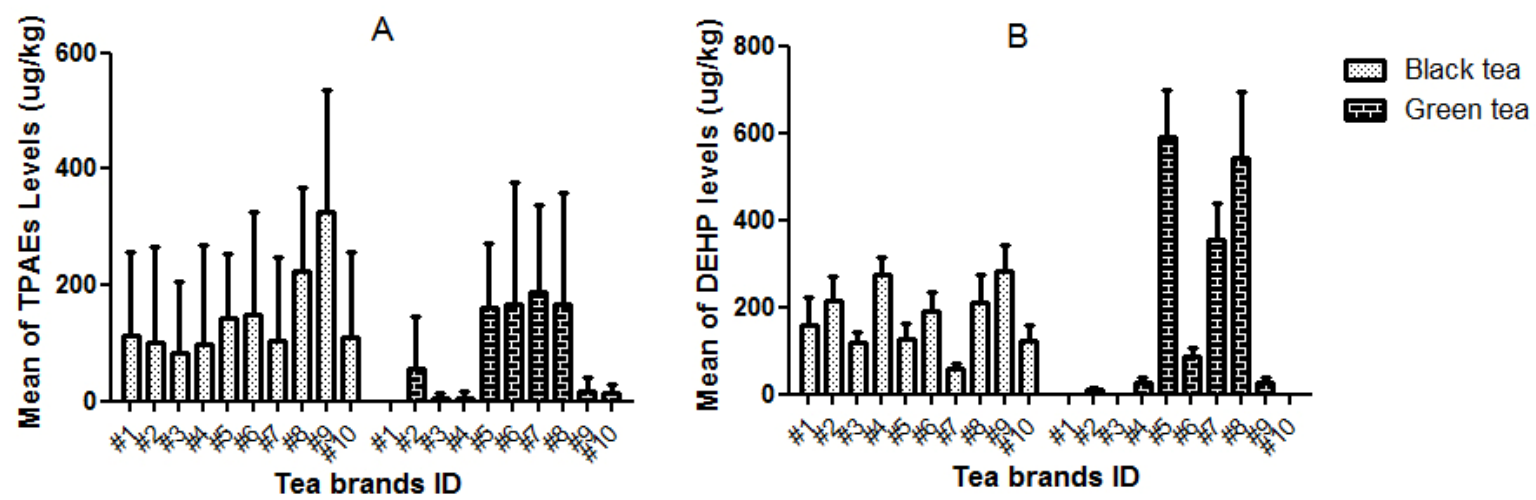

Figure 3: PAEs levels in green and black teas from different brand. A) TPAEs levels, B) DEHP levels. Data are presented as mean \pm SD from three independent analysis

Table 2: PAEs levels in different types of tea bags ( $\mu \mathrm{g} / \mathrm{kg}$ dry tea)

\begin{tabular}{rcccccccc}
\hline & \multicolumn{4}{c}{ Black tea } & \multicolumn{4}{c}{ Green tea } \\
\cline { 2 - 9 } & Min. & Max. & Median & IQR. $^{*}$ & Min. & Max. & Median & IQR. $^{*}$ \\
\hline DEP & ND & 373 & 149.5 & $55-230.5$ & ND & ND & ND & ND \\
DEHP & ND & 281 & 135.5 & $40.7-187.5$ & ND & 590 & 204 & $98.5-397-7$ \\
DBP & ND & 276 & 93 & $13.7-143.2$ & ND & 585 & 169 & $25.5-289.2$ \\
BBP & ND & 259 & 55 & $17.2-175$ & ND & 21 & 10 & $3.7-14.7$ \\
TPAEs & ND & 1189 & 376.5 & $244.7-667.5$ & ND & 1196 & 381 & $188.7-688.2$ \\
\hline
\end{tabular}

* Interquartile range

\subsection{Human exposure estimates to PAEs from tea consumption}

The findings of the current study show considerably high amounts of phthalates in Indian teas consumed in several countries. In most populations tea is used much more frequently than coffee and more attention should be paid to the quality of tea bags used by the general population. This is of special concern for those at higher risk for adverse health effects of phthalates.

Tea is consumed in the form of infusion, therefore, in the present study, we determined the dissolved ratios of PAEs from dried tea to infusion leading to exact estimation of human exposure to PAEs via tea consumption

The amount of tea consumption is the key determinant in exposure assessment. Among tea drinkers, tea drinking habits are quite different.
In some countries, as Turkey, tea is a very popular drink and its per capita consumption is about $7.5 \mathrm{~kg}$, whereas in some other like Mexico, this amount is about $0.003 \mathrm{~kg}$ (FAO, 2015). Even in members of a family, one person drinks several cups of tea and the other one does not. Some of tea drinkers like heavy and dark tea infusion, prepared from higher amounts of dry tea and some other in its light form. In this study, human exposures were estimated based on preparation of a cup of tea using a tea bag (common form of tea bag usage) according to the following equation:

Human daily exposure $(\mu \mathrm{g} / \mathrm{kg}$ bw $/ \mathrm{d})=$

$$
\frac{C(\text { ppm }) \times V(m l / \text { time }) \times F(\text { times } / D)}{\text { Body weight }(\mathrm{kg})}
$$

Where $C$ is the concentration of PAEs in the tea infusion samples (ppb), $V$ the volume of tea conception per time (ml/time), $F$ the frequency 


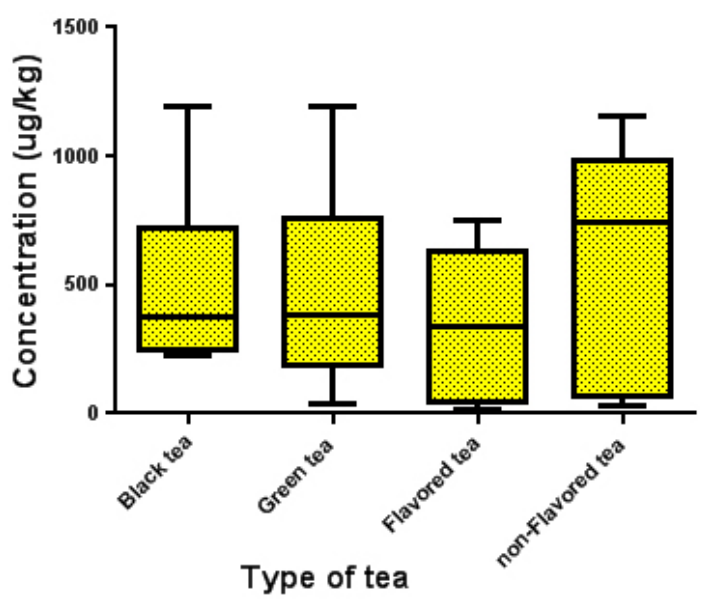

Figure 4: TPAEs levels in green, black, flavored and non-flavored tea bags. Data are presented as median (max, min)

of tea conception (times/Day), and abs. the absorption rate.

Concentration of PAEs in the tea infusion samples are presented in Table 2. Volume of tea consumption per time was considered $250 \mathrm{ml}$ (volume of a typical tea cup). Three ranges were defined for frequency of tea conception per day. Some previous studies suggested that $100 \%$ of the daily orally ingested phthalates, such as DEHP and DINP, are absorbed (United States Consumer Product Safety Commission, 2010). Based on this information, human exposure to PAEs from tea consumption were estimated and presented in Table 3.

\subsection{Risk assessment}

According to the Environmental Protection Agency (EPA) guideline, the hazard indices (HIs) were calculated as following equation (Zheng et al., 2007):

$$
H I s=\frac{\text { Daily exposure level }}{\text { Regulation level [e.g.,TDI,MRL,ADI] }}
$$

Different expert panels in Europe and America, such as the US Food and Drug Administration, European Food Safety Authority (EFSA) based on animal studies recommended values for human exposures to PAEs that are summarized in table 4 (Yen, Lin-Tan, \& Lin, 2011). The EPA also has established a maximum admissible concentration (MAC) value of $6 \mu \mathrm{g} / \mathrm{L}$ for DEHP in water (Farahani, Norouzi, Dinarvand, \& Ganjali, 2007).

\subsection{Study limitations and strengths}

The main limitation of this study is that we only measured phthalates in tea samples, and not the level in the human body. We analyzed 10 common brands of teabags used in Iran, but considering nearly similar results in all brands, and given that all samples were from teas imported from India (Ceylon), contamination of other tea brands with the same country of origin is highly probable and further investigation is recommended.

\section{Conclusions}

We found considerably high levels of phthalates in teabags used in Iran, prepared by Indian (Ceylon) imported tea. However, comparison of the estimated human exposure to PAEs from tea consumption with their permissible levels indicates that the HIs for phthalates of all teabags were far below 1 , which implies that the daily exposure levels are below regulation levels. Therefore, the usual habit of tea drinking, even 5 cups of tea/day, would not have harmful consequences for human health. However, it should be considered that tea consumption is not the only means of exposure to phthalates and several other sources for human exposure have been identified. The current findings could be useful in comprehensive phthalates risk assessment programs. 
$76 \mid$ Amin et al.

Table 3: Human exposure estimates to PAEs from tea consumption ( $\mu \mathrm{g} / \mathrm{kg}$ bw/Day). Estimated from mean concentration of PAEs in tea samples))

\begin{tabular}{|c|c|c|c|c|c|c|}
\hline & \multicolumn{3}{|c|}{ TPAEs } & \multicolumn{3}{|c|}{ DEHP } \\
\hline & Up to 1 cups $/ d$ & Up to 3 cups $/ d$ & Up to 5 cups $/ \mathrm{d}$ & Up to 1 cups/d & Up to 3 cups/d & Up to 5 cups $/ \mathrm{d}$ \\
\hline Black tea & $2,60 \mathrm{E}-03$ & $7,80 \mathrm{E}-03$ & $1,30 \mathrm{E}-02$ & $2,90 \mathrm{E}-03$ & $8,70 \mathrm{E}-03$ & $1,30 \mathrm{E}-02$ \\
\hline Green tea & $2,30 \mathrm{E}-03$ & $6,90 \mathrm{E}-03$ & $1,15 \mathrm{E}-02$ & $4,60 \mathrm{E}-03$ & $1,38 \mathrm{E}-02$ & $2,30 \mathrm{E}-02$ \\
\hline Flavored tea & $6,20 \mathrm{E}-03$ & $1,86 \mathrm{E}-02$ & $3,10 \mathrm{E}-02$ & $5,20 \mathrm{E}-03$ & $1,56 \mathrm{E}-02$ & $2,60 \mathrm{E}-02$ \\
\hline non-Flavored tea & $2,90 \mathrm{E}-03$ & $8,70 \mathrm{E}-03$ & $145 \mathrm{e}-4$ & $2,90 \mathrm{E}-03$ & $8,70 \mathrm{E}-03$ & $1,30 \mathrm{E}-02$ \\
\hline
\end{tabular}

Table 4: Recommended exposure values to PAEs by different expert panels

\begin{tabular}{llcl}
\hline PAE & Expert panels & $\begin{array}{c}\text { Value } \\
(\mu \mathrm{g} / \mathrm{kg} \text { bw/Day })\end{array}$ & \multicolumn{1}{c}{ MRL/TDI/RfD } \\
\hline \multirow{2}{*}{ DEP } & ATSDR & 7 & MRL, acute oral exposure \\
& & 5 & MRL, chronic oral exposure \\
& US-EPA & 0.8 & RfD, chronic exposure \\
DnBP & ATSDR & 0.5 & MRL, acute oral exposure \\
& US-EPA & 0.1 & RfD, chronic exposure \\
BBP & US-EPA 0.2 & & RfD chronic exposure \\
& EU-CSTEE 0.2 & & TDI \\
DEHP & US-EPA & 0.02 & RfD chronic exposure \\
& EU-CSTEE & 0.050 & TDI \\
\hline
\end{tabular}

\section{Acknowledgements}

This study was supported by a grant from Environment Research Center, Research Institute for Primordial Prevention of Non-communicable Disease, Isfahan University of Medical Sciences, Isfahan, Iran (Grant number:294180).

\section{References}

Beizhen, H., Weihua, S., Liping, X., \& Tiefeng, S. (2008). Determination of 33 pesticides in tea using accelerated solvent extraction/gel permeation chromatography and solid phase extraction/gas chromatography-mass spectrometry. Chinese Journal of Chromatography, 26(1), 22-28.

Cabrera, C., Artacho, R., \& Gimenez, R. (2006). Beneficial effects of green tea - a review. Journal of the American College of Nutrition, 25(2), 79-99.
Chacko, S. M., Thambi, P. T., Kuttan, R., \& Nishigaki, I. (2010). Beneficial effects of green tea: a literature review. Chinese Medicine, 5(1), 13. doi:10.1186/1749-85465-13

Del Carlo, M., Pepe, A., Sacchetti, G., Compagnone, D., Mastrocola, D., \& Cichelli, A. (2008). Determination of phthalate esters in wine using solid-phase extraction and gas chromatography-mass spectrometry. Food Chemistry, 111(3), 771-777. doi:10.1016/j.foodchem.2008.04.065

Di Bella, G., Saitta, M., La Pera, L., Alfa, M., \& Dugo, G. (2004). Pesticide and plasticizer residues in bergamot essential oils from calabria (italy). Chemosphere, 56(8), 777-782. doi:10.1016/j.chemosphere. 2004. 04.024

Du, L., Ma, L., Qiao, Y., Lu, Y., \& Xiao, D. (2016). Determination of phthalate esters in teas and tea infusions by gas chromatography-mass spectrometry. Food chemistry, 197, 1200-1206. 
Ermer, J. \& Miller, J. H. M. (2006). Method validation in pharmaceutical analysis: a guide to best practice. John Wiley \& Sons.

FAO. (2015). Tea consumption statistics. Retrieved from http:/ faostat3.fao.org

Farahani, H., Norouzi, P., Dinarvand, R., \& Ganjali, M. R. (2007). Development of dispersive liquid-liquid microextraction combined with gas chromatography-mass spectrometry as a simple, rapid and highly sensitive method for the determination of phthalate esters in water samples. Journal of Chromatography A, 1172(2), 105-112. doi:10 . 1016/j.chroma.2007.10-001

Glue, C., Platzer, M. H., Larsen, S. T., Nielsen, G. D., Skov, P. S., \& Poulsen, L. K. (2005). Phthalates potentiate the response of allergic effector cells. Basic \& Clinical Pharmacology \& Toxicology, 96(2), 140-142. doi:10.1111/j.1742-7843.2005.pto960208.x

Gupta, S., Saha, B., \& Giri, A. K. (2002). Comparative antimutagenic and anticlastogenic effects of green tea and black tea: a review. Mutation Research-reviews in Mutation Research, 512(1), 37-65. doi:10.1016/ S1383-5742(02)00024-8

Han, Q., Mihara, S., \& Fujino, T. (2014). Multi-Element Detection in Green, Black, Oolong, and $\mathrm{Pu}$-Erh Teas by ICP-MS. Biochem. Physiol. 3, 2.

Heudorf, U., Mersch-Sundermann, V., \& Angerer, J. (2007). Phthalates: toxicology and exposure. International Journal of Hygiene and Environmental Health, 210(5), 623-634. International Workshop on Childrens Environment in Central Europe Threats and Chances, Osnabruck, GERMANY, NOV 21-24, 2006. doi:10.1016/j. ijheh.2007.07.011

Kamrin, M. A. (2009). Phthalate risks, phthalate regulation, and public health: a review. Journal of Toxicology and Environmental Health-part B-critical Reviews, 12(2), 157174. doi:10.1080/10937400902729226

Karimi, G., Hasanzadeh, M. K., Nili, A., Khashayarmanesh, Z., Samiei, Z., Nazari, F., \& Teimuri, M. (2008). Concentrations and health risk of heavy metals in tea samples marketed in iran. Pharmacology, 3, 164-174. Retrieved from http:
/ / pharmacologyonline . silae . it / files / newsletter/2008/vol3/17.Karimi.pdf

Latini, G. (2005). Monitoring phthalate exposure in humans. Clinica Chimica Acta, 361(12), 20-29. doi:10.1016/j.cccn.2005.05.003

Lin, D. H., Zhu, L. Z., He, W., \& Tu, Y. T. (2006). Tea plant uptake and translocation of polycyclic aromatic hydrocarbons from water and around air. Journal of Agricultural and Food Chemistry, 54(10), 36583662. doi:10.1021/jf052909c

Lo Turco, V., Di Bella, G., Potorti, A. G., Fede, M. R., \& Dugo, G. (2015). Determination of plasticizer residues in tea by solid phase extraction-gas chromatography-mass spectrometry. European Food Research and Technology, 240(2), 451-458. doi:10.1007/ s00217-014-2344-3

Lu, Y., Du, L., Qiao, Y., Wang, T., \& Xiao, D. (2015). Determination of phthalate esters in tea by gas chromatography-mass spectrometry. In T.-C. Zhang \& M. Nakajima (Eds.), Advances in applied biotechnology: proceedings of the 2nd international conference on applied biotechnology (icab 2014)volume $i$ (pp. 305-315). Berlin, Heidelberg: Springer Berlin Heidelberg. doi:10.1007/ 978-3-662-45657-6_33

Martino-Andrade, A. J. \& Chahoud, I. (2010). Reproductive toxicity of phthalate esters. Molecular Nutrition \& Food Research, 54(1), 148-157. doi:10.1002/mnfr. 200800312

Mohamed, M. A. \& Ammar, A. S. (2008). Quantitative analysis of phthalates plasticizers in traditional egyptian foods (koushary and foul medams), black tea, instant coffee and bottled waters by solid phase extractioncapillary gas chromatography-mass spectroscopy. American Journal of Food Technology, 3(5), 341-346. doi:10 . 3923 / ajft . 2008.341.346

Montuori, P., Jover, E., Morgantini, M., Bayona, J. M., \& Triassi, M. (2008). Assessing human exposure to phthalic acid and phthalate esters from mineral water stored in polyethylene terephthalate and glass bottles. Food Additives and Contaminants, 25(4), 511-518. doi:10.1080/ 02652030701551800 
Qin, F. \& Chen, W. (2007). Lead and copper levels in tea samples marketed in beijing, china. Bulletin of Environmental Contamination and Toxicology, 79(3), 247-250. doi:10.1007/s00128-007-9008-y

Shah, S. K. \& Pate, V. A. (2016). Tea production in india: challenges and opportunities. Journal of Tea Science Research, (5), 1-6. doi:10.5376/jtsr.2016.06.0005

Shaltout, A. A., Abdel-Aal, M. S., Welz, B., \& Castilho, I. N. B. (2013). Determination of $\mathrm{cd}, \mathrm{cu}, \mathrm{ni}$, and $\mathrm{pb}$ in black tea from saudi arabia using graphite furnace atomic absorption spectrometry after microwaveassisted acid digestion. Analytical Letters, 46(13), 2089-2100. doi:10.1080/00032719. 2013.784918

Shen, F.-M. \& Chen, H.-W. (2008). Element composition of tea leaves and tea infusions and its impact on health. Bulletin of Environmental Contamination and Toxicology, 80(3), 300-304. doi:10.1007/s00128-0089367-z

United States Consumer Product Safety Commission. (2010). Overview of phthalates toxicity. Retrieved from https://www.cpsc. gov/s3fs-public/phthalover.pdf

Yen, T.-H., Lin-Tan, D.-T., \& Lin, J.-L. (2011). Food safety involving ingestion of foods and beverages prepared with phthalate-plasticizer-containing clouding agents. Journal of the Formosan Medical Association, 110(11), 671-684. doi:10.1016/j.jfma.2011.09.002

Zheng, N., Wang, Q., Zhang, X., Zheng, D., Zhang, Z., \& Zhang, S. (2007). Population health risk due to dietary intake of heavy metals in the industrial area of huludao city, china. Science of the Total Environment, 387(1-3), 96-104. doi:10.1016/ j.scitotenv.2007.07.044 